\title{
Progress in Textile Reinforced Ductile Cementitious Composite for Structural Retrofitting
}

\author{
Ali N Al-Gemeel ${ }^{1,2}$ and Yan Zhuge ${ }^{1 *}$ \\ ${ }^{1}$ School of NBE, University of South Australia, Australia \\ ${ }^{2}$ College of Engineering, University of Babylon, Iraq
}

*Corresponding author: Yan Zhuge, Professor in Structural Engineering, School of Natural \& Built Environments, University of South Australia, Australia.

Received Date: July 23, 2019

Published Date: August 05, 2019

\begin{abstract}
This paper presents a review of literature on the innovation of textile reinforced mortar (TRM) and its applications in structural retrofitting fields. The structure of this paper is focused on the definition of this composite along with its characterization and the most common recent applications on structural retrofitting of concrete and masonry structures. The technique has dragged a respectable research interest in the construction fields due to its promising characteristics, ease of application and competitive cost. More research is required to cover many aspects such as the matrix used to bond textile fibres. More attention is required on applying this new type of textile fibre composite material in the construction field.
\end{abstract}

Keywords: Textile reinforced mortar; Fibre; Retrofitting; Concrete structures

\section{Fibre Textile Reinforced Mortar (TRM)}

TRM includes textile fibres made out of inorganic matrix reinforced with continuous knitted or non- knitted fibres. This can be woven at least in two directions to make a fabric mesh; cementitious material is an example for the matrix to impregnate that fabric [1]. Cement-based matrix has an excellent vapor permeability, a good resistance to fire and a good applicability, which means it can successfully be used on wet surfaced at low temperature [2].

TRM is a wide category comprising high strength concrete or mortars and multifilament-Yarns of glass, polymer, or carbon. The cementitious matrix is made from fine aggregate with the maximum size ranging from 1 to $2 \mathrm{~mm}$, binder with a volumetric content of approximately $40-50 \%$, and water with water to binder ratio of about 0.3 . The high binder content is essential for workability and developing the bond between the fibres and the surrounded matrix. The composite is appropriate for both strengthening existing structures and producing new high-performance constructional elements.

TRM composites are characterized by its good tensile performance and high ductility due to the multi-cracks' tolerance. The structure of continuous fibres consists of several yarns of thousands of individual filaments with a diameter of approximately 5-25 $\mu \mathrm{m}$. The yarns can be oriented in deferent directions and the amount of the yarns could be varied by depending on applied load [3]. One textile layer, at least, should be located at the extreme side of the composite, and the textile layer could be made from yarns woven in two or more directions [4].

Moreover, the matrix used to impregnate textile has been the aim of many researches to reach an excellent performance of the composites. Cementitious mortar has commonly been used to bond the textile recently. The mortar could be enriched by discrete fibres with dimensions appropriate with the textile system; polymers additives could be added to the cementitious mortar. In addition, geopolymer or lime-based mortar could also be used to impregnate the textile fibres. Since the matrix utilized is a mortar-based matrix, TRM is a very common acronym used in the literature [5].

\section{Mechanical Properties of TRM}

In the last few years, several studies have been conducted on the use of TRM technology in strengthening concrete and masonry structures [6-8]. TRM techniques have been proven a promising alternative to the Fibre reinforced polymers (FRP) technology in cases where FRP technology has some drawbacks. For example, FRP 
is classified as a poor resistant technique to fire due to epoxy-based resin of organic polymer, typically used in FRP. Organic material, unless isolated from the fire, is flammable and not able to withstand high temperature above the glass transition, experimentally ranging from $60^{\circ}$ to $82^{\circ}$, this might be accompanied by releasing hazard fumes [9]. Due to the heterogeneity of the composite material components, a complex behavior has been observed through investigations. The tensile behavior was experimentally studied and numerically modeled to improve the knowledge for future studies and applications [10,11]. The tensile performance of cement-based composite is different from that of polymericbased composites because of the low ductility compared with the organic matrix. In the polymer-based systems, the strain capacity in tension is bigger than that of fibres resulting in an elastic behavior up to the failure point; such behavior is presented by FRP material. However, the inorganic matrixes where the ultimate strain is much less than that of the reinforcement, cracks appear before fibres reach its maximum strain. At this stage, the reinforcement is bridging at the cracked sections and carrying the entire tension. It should be mentioned that the fibre content should be over the critical value that is found to be $1-3 \%$ fraction volume of the composite. Avoiding a catastrophic failure in the matrix and making the reinforcing able to carry additional load can be achieved at contents above the critical values. Fibre geometry and the interface bond between the matrix and the fibre are important to achieve the ductile performance, and composite strength and toughness [12]. Adopting a TRM strengthening system may offer many advantages, such as a cost-efficient technique that can be simply applied as a seismic strengthening system or repairing layers. Additionally, due to the use of inorganic matric rather than the epoxy- based resin, TRM may address the disadvantages of FRP technique. TRM has the following advantages: better resistance to high temperature; easy to apply on damped surfaces; not classified as a hazardous material; sufficiency of vapor permeability [5].

\section{Types of mortar used in TRM}

Cement-based mortar (cement, sand and water) was used as a matrix in TRM composite in some investigations such as $[6,13]$. Inorganic hydraulic cement and acrylic- modified cement past, commercially available, were mixed with fine aggregate as utilized by Francisco et al. [14]. In an investigation by Marcari, et al. [7], a dry binder consisted of a hydraulic lime mortar with geo-binder and reactive components were mixed with a water to binder ratio of 1:4.9. Silica and Fly ash were used with the cementitious-based mortar to reduce the alkali component compared with Portland cement and used as bond agent in a study by Gopinath et al. [15]. A paste of cement and water only was used to impregnate a fabric mesh in a study conducted by Peled et al. [12] to study the effect of fabric geometry on the reinforcement performance of textile composite.

A binder of Cement combined with $1.8 \%$ weight of polymers was conducted by Raoof, et al. [16], water to binder ratio of about 0.23 was utilized. The mixture resulted in a mortar with $39.2 \mathrm{MPa}$ and 9.8 MPa compressive and flexural strength respectively. It was found that the presence of polymers in the cementitious mortar was essential to ensure excellent bond between the strengthening layer and the substrate when the composite applied for repairing existing concrete structures. In studies by Larrinaga et al. [11] and Larrinaga et al. [10] chopped polymers and fine sand with the particle size of $0.6 \mathrm{~mm}$ were mixed with cement paste to get cement-based mortar able to permeate into the fibres. A resin with a content of less than $5 \%$ was also added to the mortar.

In very recent research, Al-Gemeel and Zhuge have produced a new generation of TRM where they used engineered cementitious composite (ECC) to bond basalt textile fibres $[17,18]$. It was found that ECC could be a very successful cement-based matrix to impregnate textile fibres due to the strain-hardening performance and the high workability.

\section{Stress-strain behaviour of TRM under tension}

A typical stress-strain diagram under tension for the TRM material is presented in Figure 1. The curve can be divided into three stages. The first zone is linear and starts from the starting point in the curve up to the point where a first crack starts. At this stage the composite stiffness depends on the stiffness of the mortar. The first crack appears as the load exceeds the tensile strength capacity of the matrix; after the first crack occurs, the textile reinforcement starts carrying the applied force at cracked sections and the curve moves to the second zone. The interfacial bond initiates tensile force again in the matrix resulting in the occurrence of new cracks. The width and number of cracks are directly affected by the strain of the matrix, the bond between the fibres and surrounding matrix, and the characteristics of the reinforcement and its rate. When no further cracks appear within the specimen's cross section, this identifies the end of this stage and the conventional commencement of the third stage $[5,11]$. In the third stage, textile fibres only carry the tensile force and the material behaves linearly. The slope of the stress-strain curve may be parallel to that of the textile fibres under tension; and the slope is lower than the stress-strain linear trend of the first stage. It was detected that the stiffness in this stage is 10-30\% smaller than the stiffness of the textile material itself [11]. However, a new study conducted by De Santis et al. [5] revealed that the modulus of elasticity and loading capacity in the third stage are close to that of dry textile but in some cases the textile composite imposes a higher value of stiffness and a lower peak deformation compared with the dry textile. The third zone ends when the applied load reaches the peak value.

There are two integral factors cause the difference in behavior of the composite from that of textile under pure force: the lack adherence between the textile and the surrounding matrix; and the inability of matrix to impregnate every single filament that forms the roving of the textile. There are also two ways for the transmission of the load within the composite material: by the adherence between the matrix and the outer filaments of the yarns, which are surrounded by the mortar; and also, by the friction between the outer and the inner threads that form the textile fibres, where the inner-filaments has no direct bonding with the matrix $[5,11]$. 


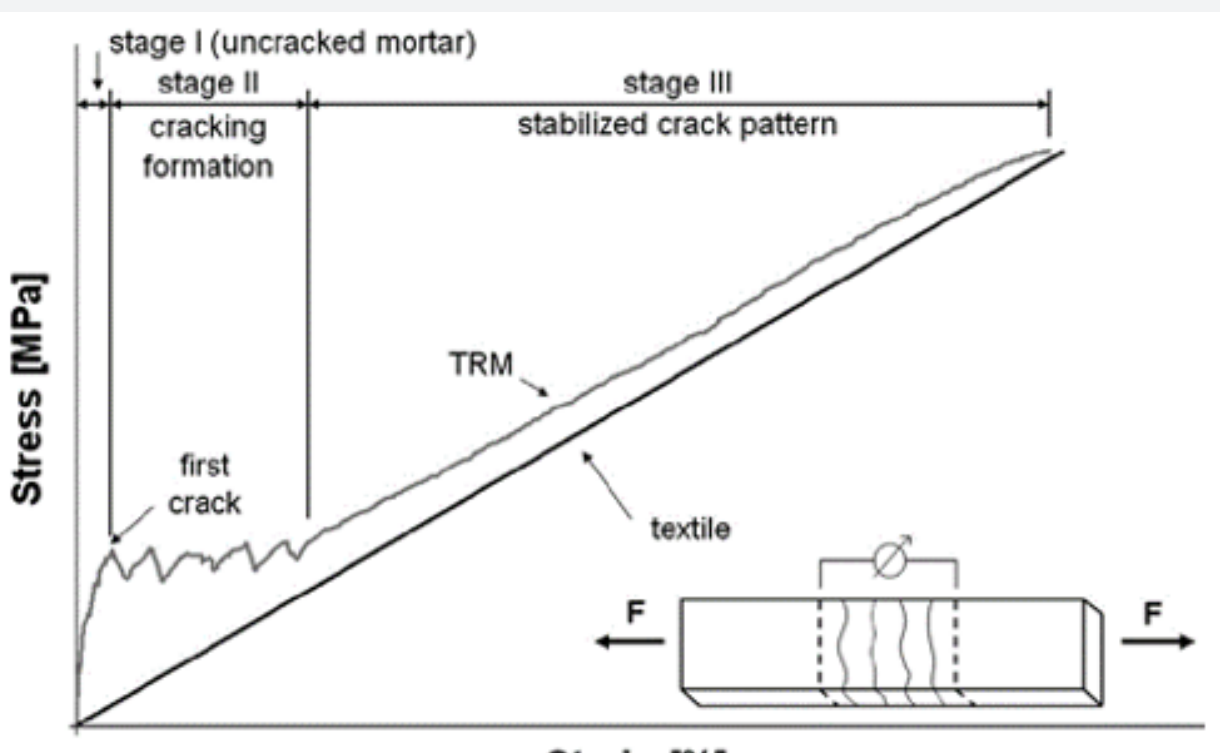

Strain [\%]

Figure 1: TRM tensile stress-strain curve (Larrinaga et al. 2014).

\section{Main Applications of TRM in Structural Retrofitting}

TRM techniques were carried out in repairing or strengthening of concrete beams, columns, and masonry structures $[19,7,20]$. Experimental and theoretical investigations have been carried out $[10,11]$; TRM have proven excellent composites in structural retrofitting. TRM can be applied in multiple layers on the extreme surface of the structural element with a limitation of up to four layers. Textile fibres can be employed on each layer in different orientations so that the direction of the textile layers could be adjusted upon the load imposed on the structural element. There is a possibility to apply more layers of textile reinforcement in different directions to recruit the fibres for the exact functionality needed. The particle size utilized in the cementitious matrix is very small, up to $1 \mathrm{~mm}$, and the textile fibre has a small cross-section. This opens up opportunities in applications of new thin structural elements with a thickness of 10 to $20 \mathrm{~mm}$. Also, there is no need for minimum cover to prevent the reinforcement from getting rusted as needed for normal steel reinforcement. Therefore, there is no extra thickness to the TRM. Such advantages can make TRM a lightweight strengthening or repairing system for structures [21]. Some applications of TRM are detailed in the following sections.

\section{Protective layer}

A protective action is anticipated in the case of repaired structures by TRM. Since textile composites exhibit multi-cracks behavior, this could be a desirable in bridging the existing cracks in substrate structures and protecting the concrete and the reinforcement from water, gases and ions permeation. The ability of TRM in healing itself with fine cracks and low ingress and capillary section gives the material the advantages to apply as a protective material. Orlowsky, et al. [22] in Mechtcherine, et al. [3] used TRM to repair dam pillars in Germany under real structural conditions. The structure had gigantic cracks (0.1-3mm width); the strengthening layers were applied to dissipate the existing cracks in the substrate structure into multi-cracks in the TRM strengthening layer. Although cracks movements were observed in the substrate, no visible cracks were notified in the repairing layer after a period of 6 months. Moreover, it was showed the ability of TRM to seal a residential building against water pressing load [23]; most residential buildings are not protection-designed from the pressure of a rising level of groundwater. The permeation of water within TRM was investigated by Mechtcherine, et al. [22]. Water flow for pre-cracked TRM specimens was measured after the specimens were stored in water for 14 days. The results were compared with those for the same specimens but before sinking them in water. It was found that the permeation was $50 \%$ higher for the specimens before being stored in water. Also, there was no considerable flow rate after 21-35 day of exposure to the water. These properties, low permeation and self-healing, give the advantages for TRM in protective layers applications.

\section{Strengthening concrete roof shell}

The strengthening technique with TRM was firstly applied under practical construction conditions in Germany 2006 for retrofitting a shell roof of reinforced concrete [3]. The roof-shell with the dimensions of $27 \mathrm{~m}$ inside length, approximately $39 \mathrm{~m}$ in span and $80 \mathrm{~mm}$ in thickness, had a stretch of up to $200 \mathrm{~mm}$ deformations in the cantilevered roof due to wind and snowfall loads as shown in Figure 2a. The tensile force was, therefore, acceded in the upper side of the shell significantly. Sandblasting of the existing concrete surface and subsequent wetting process were carried out to establish an appropriate bond in the interfacial zone between the substrate and the strengthening layer. Three layers of carbon textile fibres were planted resulting in a $15 \mathrm{~mm}$ thickness of the strengthening layer combining the light weight and two-dimensional reinforcement advantages. Figure $2 \mathrm{~b}$ shows the implement of the strengthening layer on the hyper shell. 


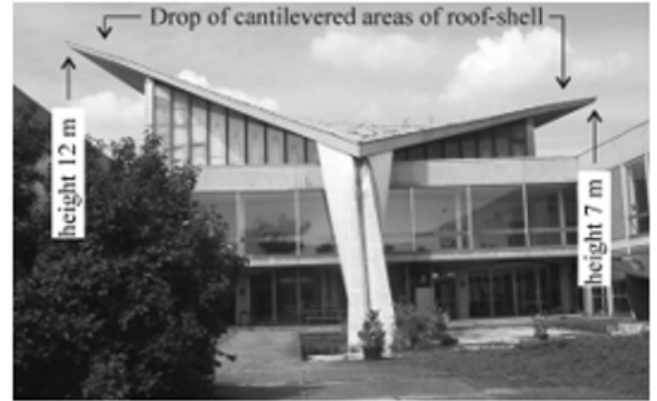

(a) Reinforced concrete shell

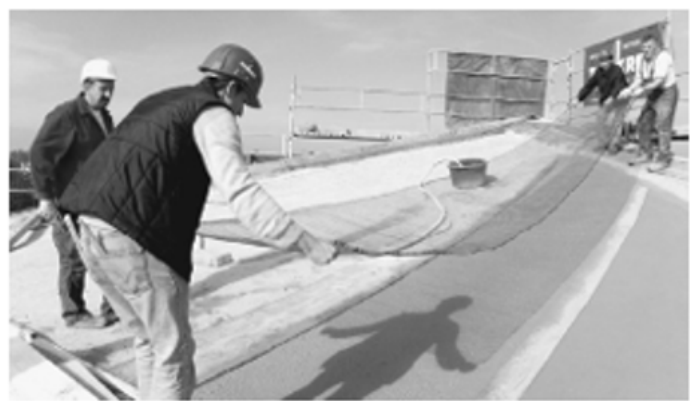

(b) Implement of the strengthening layer

Figure 2: Reinforced concrete shell, Weiland S. et al (2006) in (Mechtcherine 2013).

\section{Masonry retrofitting}

Many existing masonry structures, due to ageing, are threatening to deterioration and collapse. A typical strengthening lightweight technique is required to keep such existing structures in service.

Appling TRM materials on masonry structures by hand lay-up techniques was investigated by Marcari, et al. [7] and Almeida, et al. [24]. To establish the bond and adhesion of textile strengthening layer to masonry, wall surface was cleaned and wet; lime was also applied on the masonry surface as shown in Figure 3a. By utilizing a hand trowel, a layer of mortar was placed, the textile mesh was then placed with slightly pressing into the matrix Figure 3b. A second layer of matrix was applied as the first layers was still wet, as shown in Figure 3c. The same subsequence was repeated until the final designed layers and thickness were achieved, as demonstrated in Figure 3d. It was found that out-of-plane and in-plane load carrying capacity improved significantly by using this technique [7].

\section{TRM system for column confinement}

To find out an alternative technique to increase the column ductility and strength capacity, more investigations have been carried out recently on using TRM to confine concrete columns $[14,13,19,24]$.

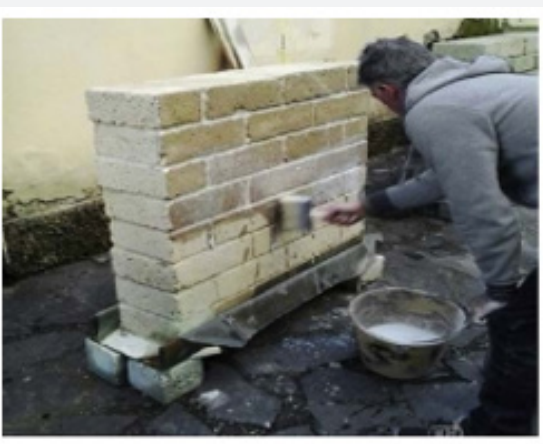

(a)

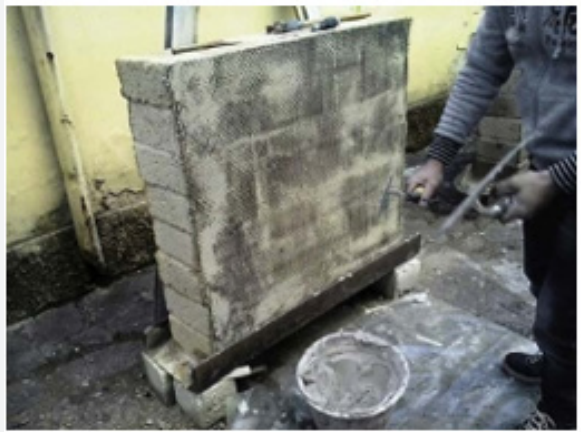

(c)

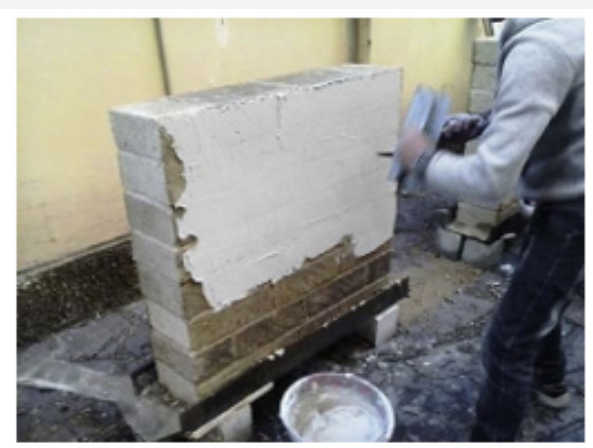

(b)

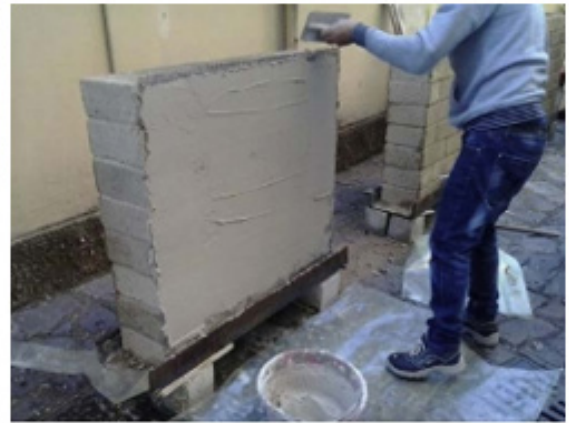

(d)

Figure 3: The application of strengthening system of masonry wall (Marcari, Basili and Vestroni 2017).

TRM layers made from carbon textile fibres and cementbased matrix were used to confine short concrete columns in an investigation conducted by Triantafillou et al. [24]. Two column cross sections were studied, circular with the diameter of $150 \mathrm{~mm}$ and square with the section area of $250 * 250 \mathrm{~mm} 2$. To compare the inorganic-based mortar versus resin-based matrix, epoxy was applied in specimens as a matrix to impregnate textile fibres, as shown in Figure 4. The effects of the inorganic mortar strength and the number of textile layers were also investigated. 


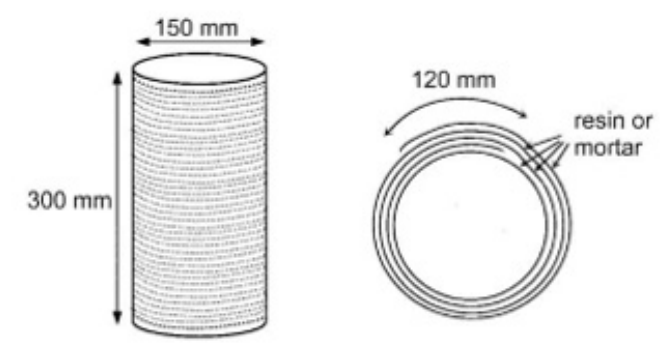

(a)|

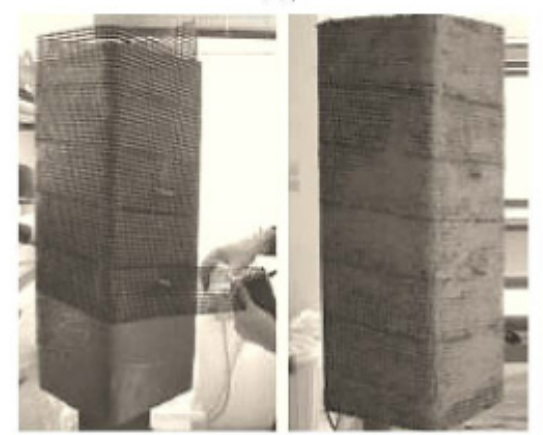

(b)

Figure 4: The application of TRM for column confinement: (a) circular column; (b) square column (Triantafillou et al. 2006).

The results revealed that comparing with the control specimens, essential improvement in axial strength was achieved. This was found to be dependent on: firstly, the number of confinement layers applied; secondly, the tensile strength of the matrix. It was found that the failure modes of the confinement, whether layer debonding or textile fracture, were determined by the stiffness of the matrix. Moreover, compared with specimens of epoxybased matrix, using cement-based mortar with textile resulted in decreased confinement effectiveness in the order of $50 \%$ and $80 \%$ for strain and strength respectively. The failure mechanism of the specimens confined by textile bonded by inorganic-based mortar was less sudden compared to that of their counterparts of textile impregnated by resin. Such behavior could be caused by the fracture of individual fibre that was propagating slowly to the neighboring bundle of the textile. The author recommended that the mentioned percentages were very much dependent on the matrix; and using a modified constituent mortar could increase the effectiveness of the confinement. However, such task was not investigated.

Furthermore, the effectiveness of the TRM confinement on rectangular concrete columns was found to be similar to that of their resin-based mortar counterparts, except when low numbers of textile were applied. In terms of ultimate strain, the results indicated that specimens confined by TRM were slightly inferior compared with their epoxy-impregnated textile counterparts. It was strongly recommended that more research toward mortar properties optimization was needed for an effective using of this technique.

\section{Summary}

In recent years, TRM has been applied to structural retrofitting of concrete and masonry structures. Compared to conventional retrofitting methods using steel for FRP, TRM has advantages of good fire resistance, easy application on wet and damped surface and lower cost. The behaviour of TRM is dependent on both the textile fibres and the matrix. The appropriate matrix could provide a uniform stress distribution. This is fundamental to avoid a premature failure of the textile, which probably happens due to concentration of shear stress or debonding in the interfacial zone. More research is required to improve the compatibility of textile fibres with surrounding matrix. When matrix fails in maintaining a proper bond required to convey the applied load uniformly to the textile fibres, the textile fibres will become overstretched in zones where loads are concentrated, resulting in premature failure of the textile fibres.

\section{Acknowledgement}

None.

\section{Conflict of Interest}

Authors declare no conflict of interest.

\section{References}

1. Ombres L (2014) Concrete confinement with a cement based high strength composite material. Composite Structures 109: 294-304.

2. Ombres L, Verre S (2015) Structural behaviour of fabric reinforced cementitious matrix (FRCM) strengthened concrete columns under eccentric loading. Composites Part B: Engineering 75: 235-249.

3. Mechtcherine V (2013) Novel cement-based composites for the strengthening and repair of concrete structures. Construction and Building Materials 41: 365-373.

4. Bigaud D, Hamelin P (2002) Stiffness and failure modelling of 2D and 3D textile-reinforced composites by means of imbricate-type elements approaches. Computers \& structures 80(27-30): 2253-2264.

5. De Santis S, Carozzi FG, de Felice G, Poggi C (2017) Test methods for textile reinforced mortar systems. Composites Part B: Engineering 127: 121-132. 
6. Elsanadedy HM, Almusallam TH, Alsayed SH, Al-Salloum YA (2013) Flexural strengthening of RC beams using textile reinforced mortarExperimental and numerical study. Composite Structures 97: 40-55.

7. Marcari G, Basili M, Vestroni F (2017) Experimental investigation of tuff masonry panels reinforced with surface bonded basalt textile-reinforced mortar. Composites Part B: Engineering 108: 131-142.

8. Raoof SM, Koutas LN, Bournas DA (2017) Textile-reinforced mortar (TRM) versus fibre- reinforced polymers (FRP) in flexural strengthening of RC beams. Construction and Building Materials 151: 279-291.

9. Triantafillou TC, Papanicolaou CG, Zissimopoulos P, Laourdekis T (2006) Concrete Confinement with Textile-Reinforced Mortar Jackets. Structural Journal 103(1): 28-37.

10. Larrinaga P, Chastre C, San-José JT, Garmendia L (2013) Non-linear analytical model of composites based on basalt textile reinforced mortar under uniaxial tension. Composites Part B: Engineering 55: 518-527.

11. Larrinaga P, Chastre C, Biscaia HC, San-José JT (2014) Experimental and numerical modeling of basalt textile reinforced mortar behavior under uniaxial tensile stress. Materials \& Design 55: 66-74.

12. Peled A, Bentur A (2003) Fabric structure and its reinforcing efficiency in textile reinforced cement composites. Composites Part A: Applied Science and Manufacturing 34(2): 107-118.

13. García D, Allonso P, San-Josi J, Garmendia L (2010) Confinement of medium strength concrete cylinders with basalt Textile Reinforced Mortar. ICPIC 2010-13 ${ }^{\text {th }}$ International Congress on Polymers in Concrete.

14. De Caso y Basalo FJ, Matta F, Nanni A (2012) Fiber reinforced cementbased composite system for concrete confinement. Construction and Building Materials 32: 55-65.

15. Gopinath S, Iyer NR, Gettu R, Palani G, Murthy AR (2011) Confinement effect of glass fabrics bonded with cementitious and organic binders. Procedia Engineering 14: 535-542.
16. Raoof SM, Koutas LN, Bournas DA (2017) Textile-reinforced mortar (TRM) versus fibre- reinforced polymers (FRP) in flexural strengthening of RC beams. Construction and Building Materials 151: 279-291.

17. AL-Gemeel AN, Zhuge Y (2018) Experimental investigation of textile reinforced engineered cementitious composite (ECC) for square concrete column confinement. Construction and Building Materials 174: 594-602.

18. Al-Gemeel AN, Zhuge Y (2019) Using textile reinforced engineered cementitious composite for concrete columns confinement. Composite Structures 210: 695-706.

19. Ludovico MD, Prota A, Manfredi G (2010) Structural upgrade using basalt fibers for concrete confinement. Journal of Composites for Construction 14(5): 541-552.

20. Sim J, Park C, Moon DY (2005) Characteristics of basalt fiber as a strengthening material for concrete structures. Composites Part B: Engineering 36(6-7): 504-512.

21. Brückner A, Ortlepp R, Curbach M (2006) Textile reinforced concrete for strengthening in bending and shear. Materials and Structures 39(8): 741-748.

22. Mechtcherine V, Lieboldt M (2011) Permeation of water and gases through cracked textile reinforced concrete. Cement and Concrete Composites 33(7): 725-734.

23. Mott R, Brameshuber W (2008) Subsequent sealing of buildings made of textile reinforced concrete.

24. Triantafillou TC, Papanicolaou CG, Zissimopoulos P, Laourdekis T (2006) Concrete Confinement with Textile-Reinforced Mortar Jackets. Structural Journal 103(1): 28-37. 